\title{
Novos táxons em Elaphidionini e Eburiini (Cerambycidae, Cerambycinae)
}

\author{
Maria Helena M. Galileo ${ }^{1,3}$ \& Ubirajara R. Martins ${ }^{2,3}$
}

\begin{abstract}
${ }^{1}$ Museu de Ciências Naturais, Fundação Zoobotânica do Rio Grande do Sul. Caixa Postal 1188, 90001-970 Porto Alegre-RS, Brasil. galileo@fzb.rs.gov.br ${ }^{2}$ Museu de Zoologia, Universidade de São Paulo. Caixa Postal 42494, 04218-970 São Paulo-SP, Brasil. urmsouza@usp.br ${ }^{3}$ Pesquisador do CNPq.
\end{abstract}

\begin{abstract}
New taxa in Elaphidionini and Eburiini (Cerambycidae, Cerambycinae). Described in Elaphidionini: Parapantonyssus gen. nov., type species, P. ipiri sp. nov. from Guatemala; Aposphaerion nigritum sp. nov. from Bolivia. In Eburiini: Beraba tate sp. nov. from Bolivia; Eburodacrys translucidum sp. nov. from Brazil (Paraíba); E. errata sp. nov. and E. fraterna sp. nov. from Bolivia.
\end{abstract}

KEYWORDS. Aposphaerion; Beraba; Eburodacrys; new taxa; Parapantonyssus.

RESUMO. Novos táxons em Elaphidionini e Eburiini (Cerambycidae, Cerambycinae). São descritos novos táxons em Cerambycinae, Elaphidionini: Parapantonyssus gen. nov., espécie-tipo, P. ipiri sp. nov. da Guatemala (San Marcos); Aposphaerion nigritum sp. nov. da Bolívia. Em Eburiini: Beraba tate sp. nov., da Bolívia; Eburodacrys translucida do Brasil (Paraíba); E. errata sp. nov. e E. fraterna sp. nov. da Bolívia.

PALAVRAS-CHAVE. Aposphaerion; Beraba; Eburodacrys; novos táxons; Parapantonyssus.

As espécies sul-americanas das tribos Eburiini e Elaphidionini foram revistas por Martins (1999, 2005) e os gêneros de Elaphidionini ocorrentes nas Américas por Lingafelter (1998). Nesta contribuição acrescentamos em Eburiini espécies novas de Beraba Martins, 1997 e de Eburodacrys White, 1853 do Brasil e da Bolívia. Em Elaphidionini descrevemos um gênero novo da Guatemala e uma espécie nova em Aposphaerion da Bolívia.

Estudamos material do American Coleoptera Museum, San Antonio (ACMS) e exemplares do nordeste do Brasil que foram doados ao Museu de Zoologia, Universidade de São Paulo (MZSP) e material coligido recentemente na Bolívia por Sérgio A. Vanin (MZSP) e pelos autores; holótipos destas espécies bolivianas serão depositados no Museo Noel Kempff Mercado, Santa Cruz, Bolívia (MNKM).

$$
\text { Elaphidionini }
$$

\section{Parapantonyssus gen. nov.}

Etimologia, Latim, para = ao lado de, Pantonyssus nome genérico proposto por Bates, 1870.

\section{Espécie-tipo, Parapantonyssus ipiri sp. nov.}

Fronte transversal. Genas tão longas quanto os lobos inferiores dos olhos e fortemente acuminadas. Lobos oculares superiores com cinco fileiras de omatídios; tão distantes entre si quanto mais que o quíntuplo da largura de um lobo. $\mathrm{Na}$ parte inferior da cabeça, os lobos oculares inferiores são mais distantes entre si do que o ápice da gena. Palpos maxilares com o dobro do comprimento dos palpos labiais que são muito curtos. Antenas das fêmeas com onze artículos, atingem o oitavo apical dos élitros. Escapo subcilíndrico sem sulco no lado dorsal da base; comprimento igual a dois terços do antenômero III. Antenômero III com carena fina no lado interno; III-VI com espinhos no ângulo interno, gradualmente decrescentes em comprimento.

Protórax apenas mais largo do que longo. Lados do protórax arredondados e com gibosidade no centro. Pronoto com elevação transversal anterior e duas gibosidades discretas de cada lado da base. Processo prosternal, no meio, com menos de um terço da largura da procoxa. Mesosterno deprimido no centro; processo mesosternal inciso no ápice, tão largo quanto um terço da mesocoxa. Metepisternos estreitos.

Élitros pubescentes. Extremidades elitrais cortadas em curva com espinho externo e espículo no ângulo sutural. Mesofêmures lineares com dois espinhos curtos, de comprimento subigual, na extremidade. Metafêmures lineares, não atingem o ápice dos élitros; ápices com dois espinhos curtos de comprimento subigual. Metatíbias sulcadas. Metatarsômeros I tão longos quanto II+III.

Discussão. Parapantonyssus gen. nov., pelas extremidades dos meso- e metafêmures com espinho, assemelha-se a Pantonyssus Bates, 1870 e Stizocera Audinet-Serville, 1834. De Pantonyssus, separa-se pela ausência de tubérculo no mesosterno e pelos dois espinhos nos meso- e metafêmures. Em Pantonyssus, o mesosterno tem tubérculo e os meso- e metafêmures tem um espinho longo no lado externo. De Stizocera, especialmente das espécies com tubérculo lateral no protórax, difere pela pubescência nos élitros e pelas genas 
fortemente acuminadas. Em Stizocera, os élitros são glabros e as genas não são acuminadas.

Separa-se de Atylostagma White, 1853 pela presença de pubescência nos élitros e de único espinho nas extremidades dos antenômeros III e IV. Em Atylostagma, os élitros são glabros e as extremidades dos antenômeros III e IV têm dois espinhos.

\section{Parapantonyssus ipiri sp. nov.} (Fig. 1)

Etimologia. Tupi, ypyri = junto de, alusivo à semelhança com Pantonyssus.

Cabeça avermelhada. Vértice com pontos rasos. Escapo avermelhado com o extremo apical preto; esparsamente pontuado. Pedicelo e flagelômeros, pretos. Protórax avermelhado. Pronoto com pontuação esparsa e aspecto brilhante. Esternos torácicos avermelhados. Élitros avermelhados com extremidade preta; com pontuação densa, pontos maiores na metade basal e gradualmente mais finos em direção ao ápice. Pubescência elitral pouco evidente na base e manifesta para o ápice. Fêmures vermelho-alaranjados com as extremidades pretas. Tíbias e tarsos pretos. Urosternitos acastanhados.

Dimensões em $\mathrm{mm}$, holótipo fêmea. Comprimento total, 20,1; comprimento do protórax, 3,0; maior largura do protórax, 3,2; comprimento do élitro, 16,1; largura umeral, 4,5 .

Material tipo. Holótipo fêmea, GUATEMALA, San Marcos: La Fraternidad (1600 m), VI.2000; J. Monzon col. (ACMS).

\section{Aposphaerion nigritum sp. nov.}

(Fig. 2)

Tegumento preto, brilhante, menos urosternitos, avermelhados. Fronte pontuada. Lobos oculares superiores com seis fileiras de omatídios; tão distantes entre si quanto a largura de um lobo. Escapo com sulco no lado dorsal da base; esparsamente pontuado. Antenômero III bicarenado, sulcado, com espinho apical externo curto. Espinhos nos ápices dos antenômeros III a VIII nas fêmeas e III-V nos machos, com comprimentos gradualmente decrescentes. Antenas atingem a extremidades dos élitros, do macho, no terço apical do antenômero VIII nos machos e no ápice do antenômero IX nas fêmeas.

Protórax com pontos esparsos, menos na constrição basal, densamente pontuada. Mesepimeros e metepisternos cobertos por pubescência esbranquiçada.

Élitros pontuados em toda a superfície. Extremidades elitrais cortadas em curva com espinho externo e espículo sutural. Fêmures com sulco no pedúnculo. Metatíbias bicarenadas. Urosternitos lisos.

Dimensões em mm, respectivamente holótipo macho/ parátipo fêmea. Comprimento total, 6,8/7,1; comprimento do protórax, 1,5/1,6; maior largura do protórax, 1,1/1,2; comprimento do élitro, 4,5/4,9; largura umeral, 1,4/1,6.
Material-tipo. Holótipo macho, BOLÍVIA, Santa Cruz: Buena Vista

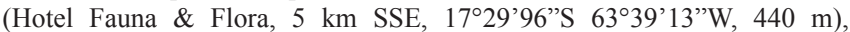
20.XI.2004, R. Clarke col (na luz ultravioleta) (MNKM). Parátipo fêmea, mesma localidade, 14-20.XI.2008, Galileo, Martins \& Vanin col. (MZSP).

Discussão. Aposphaerion nigritum sp. nov. difere de todas as espécies do gênero pelo colorido geral preto com urosternitos avermelhados.

Eburiini

\section{Beraba tate sp. nov.}

(Fig. 3)

Beraba limpida; Galileo, Martins \& Moysés, 2008: 44 non B. limpida Martins 1997.

Etimologia. Tupi, taté $=$ erro, alusivo à identificação equivocada de Galileo, Martins \& Moysés (2008).

Cabeça alaranjada, pontuada no vértice. Lobos oculares superiores com quatro fileiras de omatídios; tão afastados entre si quanto o dobro da largura de um lobo. Antenas amareladas; atingem o ápice dos élitros aproximadamente no ápice do antenômero VIII. Escapo subcilíndrico, sem sulco no lado dorsal da base.

Protórax alaranjado; tão longo quanto largo. Espinho lateral do protórax concolor e acuminado. Partes laterais do protórax pontuadas. Tubérculos dorsais do pronoto pretos e bem acuminados; superfície pronotal esparsamente pontuada, dos tubérculos para adiante e, mais densamente, dos tubérculos para a base; área centro-longitudinal com poucos pontos.

Élitros amarelo-alaranjados. Cada élitro com três manchas ebúrneas, elípticas; uma basal, convexa, alongada, quase tão longa quanto a central interna; duas centrais, contíguas e fundidas em alguns locais, iniciadas no mesmo nível, a externa mais longa que a interna. Duas costas atrás das manchas centrais. Friso epipleural ebúrneo. Uma linha ebúrnea entre as manchas ebúrneas centrais e o friso marginal. Pontuação elitral densa nos dois terços anteriores. Espinhos elitrais concolores.

Fêmures alaranjados com bases amareladas. Ápice dos meso- e metafêmures com espinho interno, concolor. Tíbias e tarsos amarelados.

Processo prosternal, mesosterno, mesepimeros, mesepisternos, metepisternos e lados do metasterno esparsamente pubescentes. Urosternitos brilhantes.

Dimensões em mm, holótipo fêmea. Comprimento total, 13,0; comprimento do protórax, 2,6; maior largura do protórax, 2,6; comprimento do élitro, 9,5; largura umeral, 3,0 .

Material-tipo. Holótipo fêmea, BOLÍVIA, Santa Cruz: Buena Vista (Hotel Fauna \& Flora), 14-20.XI.2008, Galileo, Martins \& Vanin col. (MNKM).

Discussão. Pela chave de Martins (1999) para as espécies de Beraba Martins, 1997, Beraba tate sp. nov. tem élitros com manchas elípticas ebúrneas, as centro-dorsais contíguas; tubérculos pronotais pretos e extremidades elitrais com espinhos concolores. Esses caracteres discriminam duas 

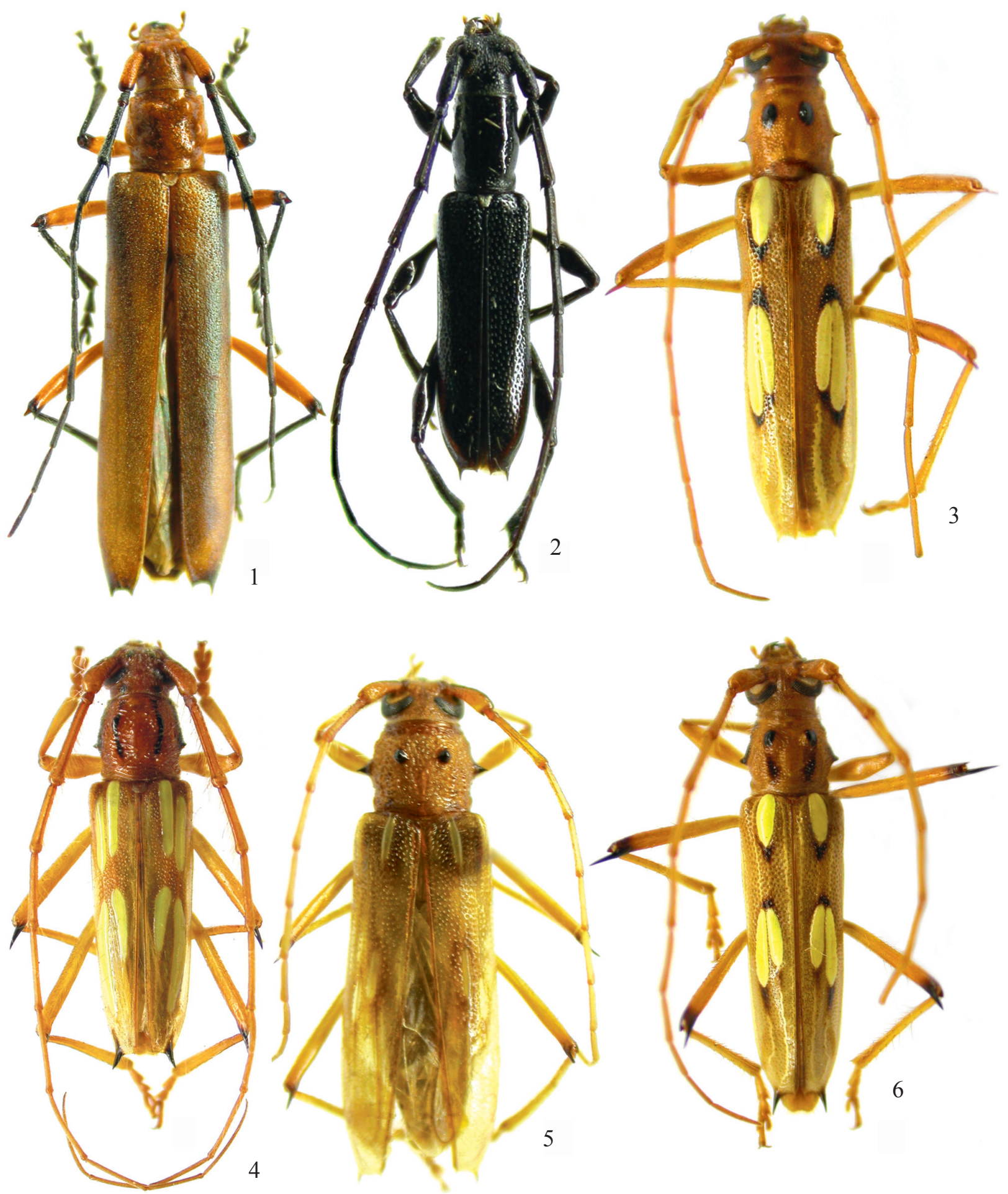

Figs. 1-6. 1, Parapantonyssus ipiri sp. nov., holótipo fêmea, comprimento $20,1 \mathrm{~mm} ; 2$, Aposphaerion nigritum sp. nov., holótipo macho, comprimento 6,8 $\mathrm{mm} ; 3$, Beraba tate sp. nov., holótipo fêmea, comprimento 13,0 mm; 4, Eburodacrys errata sp. nov., holótipo macho, comprimento 19,0 mm; 5, Eburodacrys translucida sp. nov., holótipo fêmea, comprimento 15,8 mm; 6, Eburodacrys fraterna sp. nov., holótipo fêmea, comprimento 16,2 mm.

espécies: B. limpida Martins, 1967 da Venezuela e B. marica Galileo \& Martins, 1999 da Colômbia.

Difere de B. limpida pela mancha central-externa no meio dos élitros mais longa do que a central interna; pela mancha ebúrnea da base dos élitros mais estreita e elíptico-alongada e presença de costas atrás das manchas centrais. Em $B$. limpida a mancha central-externa no meio dos élitros é quase tão longa que a central interna, a mancha ebúrnea da base dos élitros é curta e subarredondada e sem constas atrás das manchas centrais.

Separa-se de B. marica pelas manchas ebúrneas dos élitros mais alongadas, pelo espinho nos lados do protórax 
mais desenvolvido, pelos tubérculos pronotais evidentes e pela ausência de rugas transversais no pronoto. Em $B$. marica, as manchas ebúrneas são curtas, o espinho a cada lado do protórax é curto, os tubérculos pronotais são discretos e o pronoto tem rugas transversais irregulares.

\section{Eburodacrys errata sp. nov.}

(Fig. 4)

Eburocarys lepida Galileo, Martins \& Moysés, 2008: 72 non E. lepida Martins, 1973.

Etimologia. Latim, erratus = erro, alusivo à identificação equivocada de Galileo, Martins \& Moysés (2008).

Macho. Cabeça avermelhada. Tubérculos anteníferos e uma mancha a cada lado do occipício, pretas. Antenas atingem o ápice dos élitros no meio do antenômero VII. Escapo ligeiramente engrossado para o ápice com sulco pouco profundo no lado dorsal da base; pontuação grossa, mais concentrada na metade basal. Antenômero III profundamente sulcado e bicarenado.

Protórax avermelhado ou alaranjado; espinhos laterais curtos e pretos, com faixa nos lados do pronoto do espinho à borda anterior. Pronoto com tubérculos pretos envolvidos por duas faixas pretas longitudinais que se estendem de próximo da margem anterior até o adelgaçamento basal; gibosidade centro-posterior pouco demarcada e lisa; restante da superfície pronotal com rugas irregulares, sem pontos entremeados. Prosterno com rugas no centro, pouco aparentes; às vezes, com mancha preta à frente do processo prosternal. Esternos torácicos finamente pubescentes exceto o centro do metasterno.

Cada élitro com quatro manchas ebúrneas, muito alongadas: duas na base, a externa atinge o limite do terço anterior dos élitros; duas centrais, mais próximas entre si na porção anterior do que na posterior, a central interna iniciase pouco a frente da externa e posteriormente atinge o meio da externa, a central externa ligeiramente curva termina posteriormente pouco à frente do espinho apical dos élitros. Espinhos apicais dos élitros pretos, com ápices divergentes, precedidos por curta região triangular preta. Pontuação elitral abundante até as manchas ebúrneas centrais.

Fêmures laranja-amarelados; meso- e metafêmures com espinhos apicais pretos.

Fêmea. Antenas atingem a extremidade dos élitros na ponta do antenômero VIII.

Dimensões em mm, macho/fêmea respectivamente. Comprimento total, 19,0/17,5-19,5; comprimento do protórax, 4,0/3,3-3,8; maior largura do protórax, 4,4/3,7/4,3; comprimento do élitro, 13,2/12,7-14,0; largura umeral, 4,7/4,4-4,9.

Material-tipo. Holótipo macho, BOLÍVIA, Santa Cruz: Buena Vista (Hotel Fauna \& Flora), 15-28.II.2003, R. Clarke col. (MNKM).

Parátipos: BOLÍVIA, Guanay (quatro topônimos com essa dominação), fêmea, X.1995, G. Castillo col. (MZSP); Santa Cruz: Buena Vista (Hotel Fauna \& Flora, 5 km SSE,
17²9'96”S 6339'13”W, 440 m), fêmea, 7.I.2003, R. Clarke/ Zamaloa col. (na luz branca) (MCNZ); Buena Vista (Hotel Fauna \& Flora), fêmea, 14-20.XI.2008, Galileo, Martins \& Vanin col. (MZSP).

Discussão. Eburodacrys errata sp. nov. é muito semelhante a E. lepida Martins, 1973 que ocorre à Amazônia. Difere pelas manchas ebúrneas basais mais compridas, atingem o terço basal dos élitros, a externa mais longa que a interna; pelas manchas ebúrneas centrais mais longas e pela central-interna que termina próxima ao ápice elitral; pelas manchas ebúrneas não seguidas por áreas pretas.

Em E. lepida as manchas ebúrneas basais atingem o quinto basal dos élitros e são subiguais em comprimento; as manchas centrais são mais curtas e a central-interna termina no quarto apical dos élitros; as manchas ebúrneas têm áreas pretas posterior e anteriormente.

\section{Eburodacrys translucida sp. nov.}

(Fig. 5)

Etimologia. Latim, translucidus = transparente, alusivo à textura dos élitros.

Fêmea. Cabeça laranja-avermelhada. Vértice pontuado. Antenas aproximam-se, mas não atingem as pontas dos élitros. Escapo levemente engrossado para o ápice, sulcado no lado dorsal da base e densamente pontuado na metade basal. Antenômero III sulcado e bicarenado.

Protórax mais largo que longo. Lados com tubérculo preto, agudo. Pronoto com dois tubérculos projetados, pretos; superfície pronotal com rugas irregulares e pontos entremeados. Prosterno rugoso na metade posterior.

Élitros amarelados com tegumento translúcido; cada um com três faixas ebúrneas: uma no centro da base e duas centrais um pouco mais largas, afastadas entre si por distância subigual a largura da central externa que se inicia atrás do meio da central interna; a mancha basal subigual em comprimento as duas centrais. Ápice elitral com espinho externo enegrecido no ápice e mais curto que os espinhos dos ápices dos fêmures.

Fêmures amarelados com espinhos apicais pretos. Região central do metasterno e urosternitos com pêlos amarelados esparsos.

Dimensões em mm, holótipo fêmea. Comprimento total, 15,8; comprimento do protórax, 2,9; maior largura do protórax, 4,0; comprimento do élitro, 11,8; largura umeral, 4,0 .

Material-tipo. Holótipo fêmea, BRASIL, Paraíba: São João do Cariri, 15.IV.2006, M. A. B. de Gusmão col. (MZSP).

Discussão. Eburocarys translucida $\mathbf{s p . ~ n o v . ~ a s s e m e l h a - s e ~}$ a E. lancinata Napp \& Martins, 1980. Difere pelo protórax com espinho lateral desenvolvido e preto; pelas manchas ebúrneas dos élitros mais estreitas e curtas, a central inicia-se no meio da interna; pelos espinhos apicais dos élitros mais curtos que os espinhos femorais. Em E. lancinata os espinhos 
laterais do protórax são concolores, as manchas ebúrneas dos élitros são alongadas, estreitas e a central externa inicia-se no mesmo nível da interna e tem quase o dobro do comprimento da central interna, os espinhos apicais dos élitros tão longos quanto os espinhos femorais.

\section{Eburocarys fraterna sp. nov.} (Fig. 6)

Etimologia. Latim, fraternus = irmão, alusivo à semelhança com Eburodacrys sulfurifera Gounelle, 1909.

Fêmea. Cabeça alaranjada. Lobos oculares superiores com seis fileiras de omatídios; tão distantes entre si quanto a largura de um lobo. Sutura frontal profunda, larga entre os tubérculos anteníferos e os lobos oculares superiores. Antenas mais longas que os élitros. Escapo com sulco largo, profundo na base e projetado na margem interna. Antenômero III sulcado e bicarenado.

Protórax com espinho lateral preto, comprimento subigual ao do pedicelo; faixa preta do espinho até quase a orla anterior. Pronoto com dois tubérculos látero-anteriores pretos, brilhantes, arredondados no topo; mancha preta a cada um dos lados da base. Superfície pronotal com rugas irregulares, sem pontos entremeados.

Cada élitro com três manchas ebúrneas: uma elíptica alongada na base; duas centrais contíguas, iniciadas no mesmo nível, a central-externa mais longa que a externa; todas as manchas precedidas e seguidas por mancha castanha; no terço apical, duas costas das manchas centrais até quase a extremidade elitral. Extremidades elitrais com espinho externo, preto.

Meso- e metafêmures com ápice e espinho apical pretos. Metatíbias amareladas e sulcadas. Face ventral do corpo alaranjada. Meio do metasterno e urosternitos com tegumento brilhante.
Dimensões em mm, holótipo fêmea. Comprimento total, 16,2; comprimento do protórax, 3,1; maior largura do protórax, 3,7; comprimento do élitro, 11,7; largura umeral, 3,8 .

Material-tipo. Holótipo fêmea, Bolívia, Santa Cruz: Buena Vista (Hotel Flora \& Fauna), 14-20.XI.2008, Galileo, Vanin \& Martins col. (MNKM).

Discussão. Eburocarys fraterna sp. nov. assemelha-se a E. sulfurifera Gounelle, 1909 pela forma do escapo. Difere pelo espinho dos lados do protórax curto; pelos tubérculos pronotais arredondados no topo; pelas manchas pretas na base do pronoto. Em E. sulfurifera, o espinho nos lados do protórax é muito longo; os tubérculos pronotais são acuminados no topo e a base do pronoto não tem manchas pretas.

Agradecimentos. A James Wappes, American Coleoptera Museum (ACMS) e Robin Clarke pelo empréstimo de material; a Maria Avanir B. de Gusmão pela doação de espécimes para o Museu de Zoologia; a Eleandro Moysés (bolsista $\mathrm{IC} / \mathrm{CNPq} / \mathrm{MCNZ}$ ) pela execução das fotografias e preparação da estampa.

\section{REFERÊNCIAS}

Bates, H. W. 1870. Contributions to an insect fauna of the Amazon Valley. The Transactions of the Entomological Society of London, 1870: 243-335; 391-444.

Galileo, M. H. M.; U. R. Martins \& E. Moysés.2008. Cerambycidae SulAmericanos. Suplemento 2. São Paulo, Museu de Zoologia \& Museu de Ciências Naturais, $128 \mathrm{p}$.

Lingafelter, S. 1998. The Genera of Elaphidiini Thomson 1864. Memoirs of the Entomological Society of Washington, 20: 1-118.

Martins, U. R. (Org.) 1999. Cerambycidae Sul-Americanos. v. 3, São Paulo, Sociedade Brasileira de Entomologia, 418 p.

Martins, U. R. (Org.) 2005. Cerambycidae Sul-Americanos. v. 7, São Paulo, Sociedade Brasileira de Entomologia, 394 p. 